\title{
REGULAR ARTICLE Factors Affecting the First Recurrence of Noncardioembolic Ischemic Stroke
}

\author{
Tzy-Haw $\mathrm{Wu}^{1}$, Tony Hsiu-Hsi Chen ${ }^{2}$ and Ti-Kai Lee ${ }^{1,3}$ \\ ${ }^{1}$ Department of Internal Medicine, College of Medicine; \\ ${ }^{2}$ Graduate Institute of Epidemiology, College of Public Health, National \\ Taiwan University, Taipei; ${ }^{3}$ Department of Internal Medicine, En-Chu Kung Hospital, Taipei, Taiwan.
}

(Received 5 March 1999 by Editor N. Numano; revised/accepted 12 July 1999)

\begin{abstract}
Studies of the factors affecting the first recurrence of ischemic stroke have reported inconsistent findings. Types of initial stroke and the racial differences in study samples are among the explanations that may account for this inconsistency. The aims of this study were to estimate the cumulative recurrence rates of noncardioembolic ischemic stroke and identify the factors that influence the first recurrence of noncardioembolic ischemic stroke in the Taiwanese Chinese population. Four hundred and sixty-six patients with noncardioembolic ischemic stroke from thirteen hospitals in Taiwan were followed up in this study to ascertain first recurrence of noncardioembolic ischemic stroke between October 1992 and April 1995. The KaplanMeier method was used to estimate the cumulative recurrence rate. The Cox regression model was used to ascertain the significant factors affecting the first recurrence of noncardioembolic ischemic stroke. The overall cumulative recurrence rate was

Abbreviations: ASA, aspirin; CT, computed tomography; MRI, magnetic resonance imaging; ECG, electrocardiogram; BG: basal ganglion; CR: corona radiata; ACA: region of anterior cerebral artery; MCA, region of middle cerebral artery; BS, brain stem; PCA, region of posterior cerebral artery; THA: thalamus; CEREBE, cerebellum; HDL, high density lipoprotein; LDL: low density lipoprotein.

Corresponding author: Ti-Kai Lee, Department of Internal Medicine, College of Medicine, National Taiwan University, No. 7 Chung-Shan South Rd., Taipei, Taiwan. Tel.: +886 (2) 2397 0800; Fax: +886 (2) 2393 4176; E-mail: <tklee@ha.mc.ntu.edu.tw>.
\end{abstract}

$10.5 \%$ (49/466) from the follow-up period of 30 months. After adjustment for age, sex, treatment modes, and variables pertinent to blood pressure, the site of brain lesion remained a significant factor. The relative risk of first recurrence for the basal ganglion vs. the region of middle cerebral artery was 3.06 (95\% CI: 1.29-7.26). The brain lesion site was demonstrated to be an independent predictor of risk for the first recurrence of noncardioembolic ischemic stroke among the Taiwanese Chinese population. Whether this finding was also seen in other populations should be corroborated in future research. (C) 2000 Elsevier Science Ltd. All rights reserved.

Key Words: Risk factors; Ischemic stroke; Noncardioembolic stroke

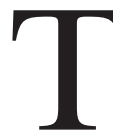

The high prevalence of recurrence after first stroke poses a major menace to stroke patients [1-11]. According to Sacco et al. [4], the rate of early recurrence within the first month is $3.3 \%$. Studies of late recurrence after an initial stroke have found recurrence rates ranging from 6 to $17 \%$ within 1 year and 19 to $42 \%$ within 5 years [3-11]. Recurrence after an initial stroke not only reduces independence of daily activity but can lead to early death $[3,11]$. To prevent recurrence, it is therefore important to identify the risk factors for first recurrence after stroke.

Although the risk factors for stroke are well established, the factors affecting the first recurrence 
after stroke are controversial and results from previous studies are inconsistent. These factors include age [5,11-13], hypertension [3,5,11,14-17] and diabetes mellitus $[8,12,15,18,19]$. Such inconsistencies may be due to methodological problems, including the differences in study design and the criteria for selection of patients, both of which may lead to variations in results.

Another possibility for these disparities is that the incidence of stroke varies between different racial groups; therefore, it can be inferred that the risk factors responsible for the recurrence after stroke may also have a similar finding. In addition, since ischemic stroke can be further categorized into the subtypes of cardioembolic ischemic stroke and noncardioembolic ischemic stroke, risk factors might not be the same for these two subtypes [4,7,20-22]. To our knowledge, the rare studies undertaken have centered on noncardioembolic ischemic stroke only. The purposes of this paper were to estimate the cumulative recurrence rate of noncardioembolic ischemic stroke and identify the risk factors for the first recurrence in noncardioembolic ischemic stroke in the Taiwanese Chinese population to provide guidance to secondary prevention.

\section{Patients and Methods}

\subsection{Data Resource}

The data used in this study were derived from a previous randomized, multicenter study that had two major purposes, including the assessment of relative efficacy of treatment using aspirin (ASA) and nicametate in reducing secondary ischemic stroke and the examination of what risk factors affect the first recurrence. The main result of the efficacy has been described in a previous research [23]. Estimating the rate of first recurrence and identifying the relevant risk factors are attempted in this study. A total of 466 patients who had the first noncardioembolic stable ischemic stroke [24] were recruited. All were hospitalized in one of the 13 participating hospitals in Taiwan from October 1992 through April 1995. These patients had strokes that included lacunar infarction, small lesion stroke, progressive stroke, and reversible ischemic neurological deficit. The criteria for select- ing patients were based on clinical symptoms (neurological deficit that persisted more than 24 hours) or positive findings obtained from computed tomography (CT) or magnetic resonance imaging (MRI). It should be noted that although brain CT is mandatory, the major criteria of stroke still depended on neurological examination. Brain MRI was only performed in patients who had brain lesions that involved the brain stem or in cases without any significant finding in the CT of the brain.

A detailed medical history of each patient was taken. Each patient received a complete physical and neurological examination. Other examinations included electrocardiogram (ECG), chest X-ray, hematological and biochemical examinations, and CT or MRI of the brain. The site of the brain lesion, as identified by brain CT or MRI, was grouped by anatomical location including the basal ganglion $(\mathrm{BG})$, the corona radiata $(\mathrm{CR})$, the region of anterior cerebral artery (ACA), the region of middle cerebral artery (MCA), the brain stem (BS), the region of posterior cerebral artery (PCA), the thalamus (THA), and the cerebellum (CEREBE) (Figure 1).

\subsection{Eligibility of Patients and Follow-Up}

The study focused on noncardioembolic ischemic stroke and excluded patients who had short anticipated survival time and patients with possible cardiogenic emboli, including those with myocardial infarction within 6 months before the stroke, chronic or paroxysmal atrial fibrillation, valvular heart disease, prosthetic valve, congestive heart disease at stroke onset, cardiomegaly, and recent systemic arterial emboli. The original design in this study attempted to follow up the condition of the patient for the cumulative rate of recurrence and the average follow-up period was 20 months. Therefore, we excluded patients who had limited survival time (e.g., cancer patients). All participants started taking aspirin or nicametate 2 to 6 weeks after the onset of the first ischemic stroke for secondary prevention. After discharge, visits to the outpatient clinic were scheduled every month for the first 6 months. Subsequently, patients were requested to visit the outpatient clinic at intervals gradually increasing from 1 month to 3 months toward the end of the study. Also, patients were advised to visit the emergency service immediately 
if their existing neurological signs deteriorated or if they experienced a new onset of a neurological sign.

\subsection{Primary End Point of First Recurrence}

The primary end point was recurrence of stroke, which was verified by the End Point Validation Committee. Recurrence was defined as a neurological deficit lasting for more than 24 hours in a new location or worsening of a previous neurological deficit lasting for more than 1 week. Head CT or MRI was mandatory in patients with recurrence of ischemic stroke or intracranial hemorrhage.

To evaluate the possible risk factors influencing the first recurrence of noncardioembolic ischemic stroke, differences in the characteristics of recurrent and nonrecurrent subjects, including age, sex, the site of brain lesion, smoking, alcohol drinking, urea nitrogen, creatinine, high-density lipoprotein (HDL), low-density lipoprotein (LDL), triglyceride, blood sugar, and systolic and diastolic pressure were compared.

\subsection{Statistical Method}

The Kaplan-Meier method was used to calculate the cumulative recurrence rate. To investigate the effect of risk factors on recurrence, univariate analysis using a Cox regression model was first performed to calculate the relative risk of recurrence. Significant variables identified in the univariate analysis $(p<0.05)$ were selected for multivariate analysis based on a stepwise Cox regression model.
The statistical criterion for entrance into and removal from the stepwise model was based on an alpha level of 0.05 . It should be noted that since this study was based on a randomized trial that assessed the relative efficacy of reducing recurrence of nicametate vs. ASA treatment, treatment modes should be taken into account while other risk factors were investigated. In addition, age and sex were two demographic variables that may affect the recurrence of stroke. These three variables were always retained in stepwise regression analysis.

\section{Results}

Table 1 shows the frequency distributions of recurrent and nonrecurrent cases with respect to relevant factors including demographic variables, brain lesion site, lifestyle, biochemical factors, treatment modes, and blood pressure. The overall cumulative rate of recurrence during the 30-month follow-up period was estimated as $10.5 \%$ (49/466). The risk for first recurrence in patients with noncardioembolic ischemic stroke increased with age, with the relative risk equal to 1.55 (95\% CI: $0.77-3.14$ ) for first recurrence in those aged over 70 years as opposed to those aged under 60 years. The relative risk of first recurrence for male vs. female was estimated as 1.09 (95\% CI: 0.61-1.93).

With regard to the site of brain lesion, the highest cumulative incidence rate was observed in the $\mathrm{BG}$ (19.2\%), followed by the CR (11.5\%), ACA
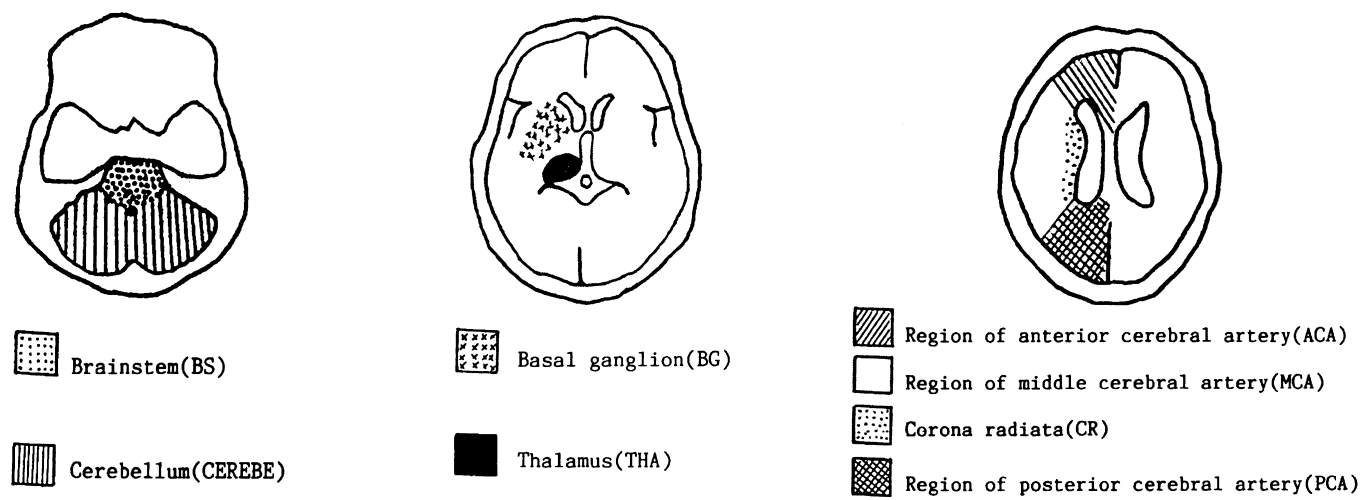

Fig. 1. The actual area of anterior cerebral artery territory, middle cerebral artery territory, posterior cerebral artery, basal ganglion, corona radiata, thalamus, brain stem, and cerebellum. 
Table 1. Results of univariate analysis on factors affecting the first recurrence of noncardioembolic ischemic stroke

\begin{tabular}{|c|c|c|c|c|c|}
\hline Variable & $\begin{array}{c}\text { Nonrecurrence } \\
(n=417)\end{array}$ & $\begin{array}{c}\text { Recurrence } \\
(n=49)\end{array}$ & Relative risk & $\chi^{2}$ & $p$ \\
\hline \multicolumn{6}{|l|}{ Age } \\
\hline$\leqslant 59$ & 153 & 15 & 1.00 & \multirow[t]{3}{*}{0.941} & \multirow[t]{3}{*}{0.625} \\
\hline $60-69$ & 151 & 18 & $1.25(0.63-2.48)$ & & \\
\hline$\geqslant 70$ & 113 & 16 & $1.55(0.77-3.14)$ & & \\
\hline \multicolumn{6}{|l|}{ Sex } \\
\hline Female & 161 & 19 & 1.00 & \multirow[t]{2}{*}{0.001} & \multirow[t]{2}{*}{0.982} \\
\hline Male & 256 & 30 & $1.09(0.61-1.93)$ & & \\
\hline \multicolumn{6}{|l|}{ Location of brain lesion } \\
\hline MCA & $105(93.7)$ & $7(6.3)$ & 1.00 & \multirow[t]{8}{*}{15.24} & \multirow[t]{8}{*}{0.033} \\
\hline BG & $84(80.8)$ & $20(19.2)$ & $3.01(1.27-7.12)$ & & \\
\hline $\mathrm{CR}$ & $69(88.5)$ & $9(11.5)$ & $2.00(0.75-5.39)$ & & \\
\hline ACA & $11(91.7)$ & $1(8.3)$ & - & & \\
\hline BS & $33(97.1)$ & $1(2.9)$ & - & & \\
\hline THA & $12(100.0)$ & $0 .(0.0)$ & - & & \\
\hline CEREBE & $5(100.0)$ & $0 .(0.0)$ & - & & \\
\hline PCA & $4(100.0)$ & $0 .(0.0)$ & - & & \\
\hline \multicolumn{6}{|l|}{ Alcohol intake } \\
\hline None & 252 & 26 & 1.00 & \multirow{4}{*}{1.202} & \multirow[t]{4}{*}{0.548} \\
\hline Rare & 146 & 21 & $1.67(0.79-3.53)$ & & \\
\hline Often & 14 & 2 & $1.50(0.33-6.81)$ & & \\
\hline Unknown & $5(1.2)$ & 0 & - & & \\
\hline \multicolumn{6}{|l|}{ Smoking } \\
\hline No & 230 & 22 & 1.00 & \multirow[t]{3}{*}{1.781} & \multirow[t]{3}{*}{0.182} \\
\hline Yes & 181 & 26 & $1.98(0.89-4.43)$ & & \\
\hline Unknown & 6 & 1 & - & & \\
\hline \multicolumn{6}{|l|}{ Urea nitrogen } \\
\hline $8-20 \mathrm{mg} / \mathrm{dL}$ & 356 & 43 & 1.00 & \multirow[t]{3}{*}{0.115} & \multirow[t]{3}{*}{0.735} \\
\hline$>20 \mathrm{mg} / \mathrm{dL}$ & 58 & 6 & $1.03(0.44-2.43)$ & & \\
\hline Unknown & 3 & 0 & - & & \\
\hline Creatinine & & & & & \\
\hline $0.6-1.4 \mathrm{mg} / \mathrm{dL}$ & 366 & 43 & 1.00 & 0.032 & 0.857 \\
\hline$>1.4 \mathrm{mg} / \mathrm{dL}$ & 47 & 6 & $1.15(0.48-2.74)$ & & \\
\hline Unknown & 4 & 0 & - & & \\
\hline HDL & & & & & \\
\hline$\geqslant 35 \mathrm{mg} / \mathrm{dL}$ & 168 & 15 & 1.00 & 3.052 & 0.082 \\
\hline$<35 \mathrm{mg} / \mathrm{dL}$ & 53 & 10 & $2.11(0.94-4.73)$ & & \\
\hline Unknown & 196 & 24 & - & & \\
\hline LDL & & & & & \\
\hline$<150 \mathrm{mg} / \mathrm{dL}$ & 138 & 15 & 1.00 & 0.030 & 0.862 \\
\hline$\geqslant 150 \mathrm{mg} / \mathrm{dL}$ & 70 & 7 & $1.02(0.41-2.50)$ & & \\
\hline Unknown & 209 & 27 & - & & \\
\hline Triglyceride & & & & & \\
\hline $50-130 \mathrm{mg} / \mathrm{dL}$ & 158 & 17 & 1.00 & 0.258 & 0.612 \\
\hline$>130 \mathrm{mg} / \mathrm{dL}$ & 237 & 30 & $1.17(0.62-2.03)$ & & \\
\hline Unknown & 22 & 2 & - & & \\
\hline Blood sugar & & & & & \\
\hline$<200 \mathrm{mg} / \mathrm{dL}$ & 370 & 41 & 1.00 & 1.077 & 0.299 \\
\hline$\geqslant 200 \mathrm{mg} / \mathrm{dL}$ & 47 & 8 & $1.61(0.75-3.43)$ & & \\
\hline Treatment modes & & & & & \\
\hline Nicametate & 212 & 32 & 1.00 & 3.679 & 0.055 \\
\hline ASA & 205 & 17 & $0.59(0.33-1.06)$ & & \\
\hline Systolic blood pressure (obtained at arrival) & $157.4 \pm 26.3$ & $161.5 \pm 29.8$ & $1.01(0.99-1.02)$ & 1.12 & 0.29 \\
\hline Systolic blood pressure (obtained during & & & & & \\
\hline admission) & $172.3 \pm 26.4$ & $180.3 \pm 27.2$ & $1.01(1.00-1.02)$ & 4.10 & 0.04 \\
\hline Diastolic blood pressure (obtained at arrival) & $91.5 \pm 14.6$ & $96.1 \pm 17.4$ & $1.02(1.00-1.04)$ & 5.05 & 0.02 \\
\hline $\begin{array}{l}\text { Diastolic blood pressure (obtained during } \\
\text { admission) }\end{array}$ & $99.8 \pm 14.1$ & $103.8 \pm 14.4$ & $1.02(1.00-1.04)$ & 4.32 & 0.04 \\
\hline
\end{tabular}

See text for abbreviations. 
Table 2. Cumulative recurrence rates (\%) by the site of brain lesion, including MCA, $\mathrm{CR}$, and $\mathrm{BG}$

\begin{tabular}{lrrr}
\hline Time (months) & MCA & CR & BG \\
\hline 3 & 0.89 & 2.60 & 4.83 \\
6 & 1.81 & 3.98 & 7.82 \\
9 & 2.82 & 3.98 & 8.92 \\
12 & 2.82 & 3.98 & 11.36 \\
24 & 8.78 & 13.31 & 18.92 \\
\hline
\end{tabular}

See text for abbreviations.

(8.3\%), MCA (6.3\%), BS (2.9\%), PCA ( $0 \%)$, THA $(0 \%)$, and CEREBE $(0 \%)$. Variation in the cumulative recurrence rates by cerebral sites reached statistical significance $\left(\chi^{2}=15.24, p=0.033\right)$.

If we took MCA as the reference group, the initial stroke found in BG had a threefold $(95 \%$ CI: 1.27-7.12) risk of first recurrence of noncardioembolic ischemic stroke compared with those in MCA. The relative risk of CR vs. MCA was 2.00 (95\% CI: 0.75-5.39). It should be noted that due to small numbers of first recurrence found in the sites of ACA, PCA, CEREBE, BS, and THA, we cannot calculate relative risk for these brain lesion sites.

Since the site of the brain lesion significantly determined the risk of first recurrence of noncardioembolic ischemic stroke, cumulative recurrence rates were calculated for $\mathrm{BG}, \mathrm{CR}$, and $\mathrm{MCA}$ identified by CT scan or MRI (Table 2 and Figure 2 ). The cumulative recurrence rates for $\mathrm{BG}$ at 6 months, 1 year, and 2 years were 7.82, 11.36, and $18.92 \%$, respectively. The corresponding figures for CR and MCA are also shown in Table 2. The

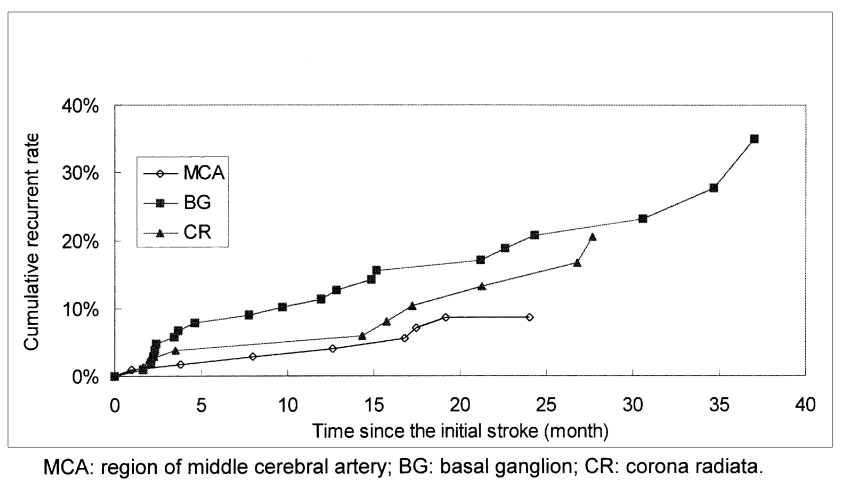

Fig. 2. Cumulative recurrence rate on first recurrence of noncardioembolic ischemic stroke by MCA, CR, and BG by brain image of first stroke by time since initial stroke. difference in the risk of first recurrence between the three locations was statistically significant ( $\mathrm{Log}$ rank test $\left.\chi_{(2)}^{2}=6.92, p=0.03\right)$.

Alcohol and smoking were associated with increased risk of first recurrence in cases of noncardioembolic ischemic stroke. The risk of first recurrence of noncardioembolic ischemic stroke in smokers was twice that in nonsmokers (95\% CI: 0.89-4.43). However, this finding was not statistically significant.

The effect of urea nitrogen and creatinine on first recurrence was not substantial. The risk of first recurrence of noncardioembolic ischemic stroke in subjects with HDL below $35 \mathrm{mg} / \mathrm{dL}$ was twice that of subjects with HDL greater than $35 \mathrm{mg} / \mathrm{dL}$. The influence of LDL on first recurrence was negligible. The relative risk for blood sugar greater than 200 $\mathrm{mg} / \mathrm{dL}$ vs. less than $200 \mathrm{mg} / \mathrm{dL}$ was 1.60 (95\%CI: 0.75-3.43), which did not reach statistical significance. The effect of triglyceride on events was not substantial.

Diastolic blood pressure on admission, systolic blood pressure, and diastolic blood pressure during admission had a significant impact on the first recurrence of noncardioembolic ischemic stroke.

A multivariate analysis (Table 3) was performed on the basis of age, sex, and treatment modes plus significant variables identified in the univariate analysis, including the site of the brain lesion, diastolic blood pressure on admission, systolic blood pressure, and diastolic blood pressure during admission. As pointed out earlier, age, sex, and treatment modes were regarded as basic variables and were always retained in the stepwise Cox regression procedure. After the analysis with the stepwise procedure, in addition to age, sex, and treatment modes, only the site of brain lesion was retained in the model. The adjusted relative risk for BG vs. MCA was 3.06 (95\% CI: 1.29-7.26). The corresponding figure for CR vs. MCA was $2.20(95 \%$ CI: 0.81-5.97). The effects of diastolic blood pressure on admission and systolic blood pressure and diastolic blood pressure during admission on the first recurrence of noncardioembolic ischemic stroke did not reach a statistically significant level and were removed from the model.

\section{Discussion}

The major finding in this study is that the risk for first recurrence of noncardioembolic ischemic 
Table 3. Multivariate analysis of prognostic factors (including age, sex, treatment modes, and the site of brain lesion) on the first recurrence of noncardioembolic ischemic stroke

\begin{tabular}{llcc}
\hline Variable & \multicolumn{1}{c}{ Level } & Relative risk & $\mathbf{9 5 \%}$ CI \\
\hline Age & \$59 years & 1.00 & \\
& 60-69 years & 1.28 & $0.57-2.87$ \\
Sex & Female & 1.69 & $0.74-3.87$ \\
& Male & 1.00 & \\
Site of brain lesion & MCA & 1.07 & $0.54-2.10$ \\
& BG & 3.00 & \\
Treatment modes & CR & 2.06 & $1.29-7.26$ \\
& Nicametate & 1.00 & \\
& ASA & 0.64 & $0.33-1.26$ \\
\hline
\end{tabular}

See text for abbreviations.

stroke among initial stroke in $\mathrm{BG}$ and $\mathrm{CR}$ was higher than that among initial stroke in MCA. The clinical implication of this finding is that the risk of first recurrence in noncardioembolic ischemic stroke should be subclassified with respect to the brain lesion site.

Our results concerning the relation between the risk of first recurrence and the site of brain lesion differ from some previous studies [5,17] in which no significant association between stroke location and recurrence was found. There are several possibilities that may account for this discrepancy. First, the definitions of events differed between our study and the conflicting studies. Our study only focused entirely on noncardioembolic ischemic stroke, whereas the other studies included both cardioembolic ischemic stroke and noncardioembolic ischemic stroke in the analysis.

Second, the classifications of cerebral lesion site in our study may be different from previous studies $[5,17]$. Our classification for the site of brain lesion was more specific than previous studies, in which "supratentorial" and "infratentorial" were used as classifications. To clarify whether the effect of the site of brain lesion on recurrence is real, it would be worthwhile to look into a more specific site of brain lesion in the future research.

A third possibility accounting for the inconsistent finding is the use of different observation periods in previous studies. Table 2 illustrates this point: the difference in the cumulative recurrence rate increases by a larger amount between BG and MCA or CR and MCA when a longer follow-up period was observed. Further research is needed to corroborate the significance of the relationship between brain lesion site and first recurrence of noncardioembolic ischemic stroke.

Regarding the site of brain lesion identified by CT or MRI, rare studies compared locations of initial stroke with those of first recurrence. Table 1 shows that the initial stroke with brain lesion identified by CT or MRI was approximately $76 \%$ (361/466), which was very close to $77 \%$ (37/49) observed for first recurrence shown in Table 4. Site of brain lesion among the initial stroke was most commonly found in MCA (31.0\%), followed by BG (28.8\%), CR (21.6\%), BS (9.4\%), THA (3.3\%), ACA (3.0\%), CEREBE (1.4\%), and PCA $(1.1 \%)$. A similar finding was observed for the first recurrence, which was ranked as follows: MCA (40.5\%), BG (18.9\%), CR (16.2\%), BS (8.1\%), THA (5.4\%), CEREBE (5.4\%), and ACA (2.7\%).

Our study found a positive association between blood pressure and first recurrence in the univariate analysis. However, this relationship became insignificant after adjustment for age, sex, treatment modes, and the site of brain lesion. This finding is in conflict with the results of some previous studies, which reported a significant association between hypertension and recurrent stroke $[3,5,11,14,15]$. However, it is difficult to make a comparison because most studies did not take into account the brain site.

Since treatment mode may interact with prognostic factors to make significant contribution to first recurrence, a separate analysis by treatment 
Table 4. Multivariate analysis of prognostic factors (including age, sex, the site of brain lesion, treatment modes, and lesion size) on the first recurrence of noncardioembolic ischemic stroke

\begin{tabular}{llcc}
\hline Variable & \multicolumn{1}{c}{ Level } & Relative risk & 95\% CI \\
\hline \multirow{2}{*}{ Age } & $\leqslant 59$ years & 1.00 & \\
& 60-69 years & 1.26 & $0.63-2.51$ \\
& $\geqslant 70$ years & 1.50 & $0.73-3.07$ \\
Sex & Female & 1.00 & \\
Site of brain lesion & Male & 1.06 & $0.59-1.90$ \\
& MCA & 1.00 & \\
Treatment modes & BG & 2.99 & $1.58-5.64$ \\
& NR & 2.35 & $1.05-5.27$ \\
Lesion size & ASA & 1.00 & \\
& $\leqslant 1 \mathrm{~cm}$ & 0.57 & $0.31-1.02$ \\
& $>1$ and $\leqslant 3 \mathrm{~cm}$ & 1.00 & \\
& $>3 \mathrm{~cm}$ & 0.55 & $0.25-1.18$ \\
& & 1.81 & $0.42-7.83$ \\
\hline
\end{tabular}

See text for abbreviations.

was therefore attempted. However, no significant factors were found in the univariate analysis after the stratification by treatment mode. We also performed a separate analysis by treatment in multivariate regression. Similarly, the estimates of relative risk of first recurrence were similar to those in Table 3, but they did not show statistical significance. Insufficient statistical power due to stratification accounts for these insignificant findings.

In addition to the variables in univariate analysis (Table 1), size may be an important factor for the first recurrence of noncardioembolic ischemic stroke. However, our study did not show size to be a significant factor because the majority of patients had lesions $(72 \%)$ less than $1 \mathrm{~cm}$ in size. Accordingly, a significant result cannot be found due to the lack of heterogeneity with respect to the size of lesion. Because of the preponderance of small lesions in our study, it could be argued that the effect of the site of brain lesion on first recurrence of noncardioembolic ischemic stroke may be confounded by the fact that such small lesions (such as lacunar infarcts) often involve the basal ganglia and the independent effect of the site of brain lesion shown in Table 3 may be attributed to small lesions rather than the site of brain lesions. To clarify this issue, we classified the size of lesion into three groups, small $(\leqslant 1 \mathrm{~cm})$, intermediate $(>1$ $\mathrm{cm}$ and $<3 \mathrm{~cm})$, and large $(\geqslant 3 \mathrm{~cm})$, and enter this factor into multivariate analysis. Results show the site of brain lesion still remained a significant predictor for first recurrence of noncardioembolic ischemic stroke after adjustment for size (Table 4). This suggests that the site of brain lesion is an

Table 5. Frequency of the site of brain lesion cross-tabulated by initial stroke and the first recurrence of noncardioembolic ischemic stroke

\begin{tabular}{|c|c|c|c|c|c|c|c|c|c|}
\hline \multirow[b]{2}{*}{ Site of initial stroke } & \multicolumn{9}{|c|}{ Site of recurrent stroke } \\
\hline & BG & MCA & $\mathbf{C R}$ & ACA & BS & THA & CEREBE & Multiple & Total \\
\hline $\mathrm{BG}$ & 6 & 8 & 0 & 0 & 0 & 0 & 1 & 0 & 15 \\
\hline MCA & 1 & 2 & 1 & 0 & 0 & 1 & 0 & 0 & 5 \\
\hline CR & 0 & 3 & 2 & 0 & 1 & 1 & 0 & 0 & 7 \\
\hline $\mathrm{ACA}$ & 0 & 0 & 0 & 0 & 1 & 0 & 0 & 0 & 1 \\
\hline $\mathrm{BS}$ & 0 & 0 & 0 & 0 & 1 & 0 & 0 & 0 & 1 \\
\hline Negative finding & 0 & 2 & 3 & 1 & 0 & 0 & 1 & 1 & 8 \\
\hline Total & 7 & 15 & 6 & 1 & 3 & 2 & 2 & 1 & 37 \\
\hline
\end{tabular}

See text for abbreviations. 
independent predictor for first recurrence of noncardioembolic ischemic stroke.

Although our study found that the first recurrence of noncardioembolic ischemic stroke varied by the site of brain lesion, including MCA, BG, and CR (Table 5), the number of recurrence for other locations was, however, relatively small. Moreover, results were only based on Taiwanese Chinese people. An ongoing research will be needed to confirm whether this finding was only confined to the specific ethnic group (Oriental ethnicity or even Chinese ancestry).

In conclusion, this study found a significant association between brain lesion site and first recurrence of noncardioembolic ischemic stroke. This result should be confirmed in future research.

This study was supported by a grant (DOH-TD-019) from Department of Health (DOH), Executive Yuan, Republic of China.

\section{References}

1. Dennis MS, Burn JP, Sandercock PA, Bamford JM, Wade DT, Warlow CP. Long-term survival after first-ever stroke: The Oxfordshire Community Stroke Project. Stroke 1993;24:796800.

2. Bamford J, Sandercock PS, Jones L, Warlow C. The natural history of lacunar infarction: The Oxfordshire Community Stroke Project. Stroke 1987;18:545-51.

3. Sacco RL, Foulkes MA, Mohr JP, Wolf PA, Hier DB, Price TR. Determinants of early recurrence of cerebral infarction: The Stroke Data Bank. Stroke 1989;20:983-9.

4. Sacco RL, Wolf PA, Kannel WB, McNamara PM. Survival and recurrence following stroke: The Framingham Study. Stroke 1982;13:290-5.

5. Hier DB, Foullkes MA, Swiontoniowski M, Sacco RL, Gorelick PB, Mohr JP, Price TR, Wolf PA. Stroke recurrence within 2 years after ischemic infarction. Stroke 1991;22: 155-61.

6. Wolf PA, Kannel WB, McGee DL, Meets SL, Bharucha NE, McNamara PM. Duration of atrial fibrillation and imminence of stroke: The Framingham Study. Stroke 1983;15:664-7.

7. Sage JI, Van Uitert RL. Risk of recurrent stroke with atrial fibrillation: Difference be- tween rheumatic and atherosclerotic heart disease. Stroke 1983;14:537-40.

8. Burn J, Dennis M, Bamford J, Sandercock P, Wade D, Warlow C. Long-term risk of recurrent stroke after a first-ever stroke: The Oxfrodshire Community Stroke Project. Stroke 1994;25:333-7.

9. Sacco RL, Shi T, Zamanillo MC, Kargman DE. Predictors of mortality and recurrence after hospitalized cerebral infarction in an urban community: The Northern Manhattan Stroke Study. Neurology 1994;44:626-34.

10. Prencipe M, Culasso F, Rasura M, Anzini A, Beccia M, Cao M, Giubilei F. Long-term prognosis after a minor stroke: 10-year mortality and major stroke recurrence rates in a hospitalbased cohort. Stroke 1998;29:126-32.

11. Jorgensen HS, Nakayama H, Reith J, Raaschou HO, Olsen TS. Stroke recurrence: Predictor, severity, and prognosis. The Copenhagen Stroke Study. Neurology 1997;48:891-5.

12. Viitanen M, Eriksson S, Asplund K. Risk of recurrent stroke, myocardial infarction and epilepsy during long term follow-up after stroke. Eur Neurol 1988;28:227-31.

13. Marquardsen J. The natural history of acute cerebrovascular disease: A retrospective study of 769 patients. Acta Neurol Scand 1969;45 (Suppl. 38):11-155.

14. Lai SM, Alter M, Friday G, Sobel E. A multifactorial analysis of risk factors for recurrence of ischemic stroke. Stroke 1994;25:958-62.

15. Alter M, Sobel E, McCoy R, Francis ME, Davanipour Z, Shofer F, Levitt LP, Meehan EF. Stroke in the Lehigh Valley: Risk factors for recurrent stroke. Neurology 1987;37:503-7.

16. Meissner I, Whisnant JP, Garraway WM. Hypertension management and stroke recurrence in a community. Stroke 1988;19:459-63.

17. Goldstein LB, Perry A. Early recurrent ischemic stroke, a case-control study. Stroke 1992; 23:1010-3.

18. Olsson T, Viitanen M, Asplund K, Eriksson S, Hagg E. Prognosis after stroke in diabetic patients: A controlled prospective study. Diabetologia 1990;33:244-9.

19. Broderick JP, Phillips SJ, O'Fallon WM, Fryc RL, Whisnant JP. Relationship of cardiac disease to stroke occurrence, recurrence, and mortality. Stroke 1992;23:1250-6. 
20. Cerebral Embolism Task Force. Cardiogenic brain embolism. Arch Neurol 1986;43:71-84.

21. Cerebral Embolism Study Group. Immediate anticoagulation of embolic stroke: A randomized trial. Stroke 1983;14:668-76.

22. Bousser MG, Eschwege E, Haguenau M, Lefaucconnier JM, Thibult N, Touboul D, Touboul PJ. AICLA controlled trial of aspirin and dipyridamole in the secondary prevention of atherothrombotic cerebral ischemia. Stroke 1983;14:5-14.
23. Lee TK, Chan KW, Huang ZS, Ng SK, Lin RT, HL Po, Yuan RY, Lai ML, Chang TW, Yan SH, Deng JC, Liu LH, Lee KY, Lie SK, Sung SM, Hu HH. Effectiveness of low-dose ASA in prevention of secondary ischemic stroke, the ASA Study Group in Taiwan. Thromb Res 1997;87:215-24.

24. Special report from the National Institute of Neurological Disorders and Stroke. Classification of cerebrovascular diseases III. Stroke 1990;21(4):637-76. 